\title{
Opportunities missed: A Cross-Sectional Survey of the Provision of Smoking Cessation Care to Pregnant Women by Australian General Practitioners and Obstetricians
}

\author{
Bar Zeev Yael, MD, MPH \\ Corresponding Author, School of Medicine and Public Health, The University of \\ Newcastle, Callaghan, New South Wales, Australia \\ yael.barzeev@uon.edu.au
}

Bonevski Billie, PhD

School of Medicine and Public Health, The University of Newcastle, Callaghan, New South Wales, Australia

Twyman Laura, PhD

School of Medicine and Public Health, The University of Newcastle, Callaghan, New South Wales, Australia

Watt Kerrianne, PhD

James Cook University, Townsville, Queensland, Australia

Atkins Lou, PhD

University College London, London, UK,

Palazzi Kerrin, MPH

Hunter Medical Research Institute, Newcastle, New South Wales, Australia

\section{Oldmeadow Christopher, PhD}

Hunter Medical Research Institute, Newcastle, New South Wales, Australia

Gould Gillian S, PhD, MA, MBChB

School of Medicine and Public Health, The University of Newcastle, Callaghan, New South Wales, Australia

This copy is the author's copy in the final version submitted and accepted. This version might differ slightly from the final edited version published in the journal. 


\section{ABSTRACT}

Introduction: Similar to other high-income countries, smoking rates in pregnancy can be high in specific vulnerable groups in Australia. Several clinical guidelines exist, including the 5As (Ask, Advice, Assess, Assist, Arrange); ABCD (Ask; Brief advice; Cessation; Discuss), and AAR (Ask, Advice, Refer). There is lack of data on provision of smoking cessation care (SCC) of Australian General Practitioners (GPs) and Obstetricians.

Methods: A cross-sectional survey explored the provision of SCC, barriers and enablers using the Theoretical Domains Framework (TDF), and the associations between them. Two samples were invited: 1) GPs and Obstetricians from a college database $(n=5,571) ; 2)$ GPs from a special interest group for Indigenous health $(n=500)$. Dimension reduction for the TDF was achieved with factor analysis. Logistic regression was carried out for performing all the 5A's and the AAR.

Results: Performing all of the 5As, ABCD, and AAR 'often and always' was reported by $19.9 \% ; 15.6 \%$, and $49.2 \%$ respectively. 'Internal influences' (such as confidence in counselling) were associated with higher performance of the 5A's (Adjusted OR 2.69 (95\% CI 1.5, 4.8), $\mathrm{p}<0.001$ ), whereas 'External influences' (such as workplace routine) were associated with higher performance of AAR (Adjusted OR 1.7 (95\% CI 1, 2.8), p=0.035).

Conclusions: Performance in providing SCC to pregnant women is low among Australian GPs and Obstetricians. Training clinicians should focus on improving internal influences such as confidence and optimism. The AAR may be easier to implement, and interventions at the service level should focus on ensuring easy, effective and acceptable referral mechanisms are in place. 


\section{IMPLICATIONS}

Improving provision of the 5A's approach should focus on the individual level, including better training for GPs and Obstetricians, designed to improve specific 'internal' barriers such as confidence in counselling and optimism. The AAR may be easier to implement in view of the higher overall performance of this approach. Interventions on a more systemic level need to ensure easy, effective and acceptable referral mechanisms are in place. More research is needed specifically on the acceptability of the Quitline for pregnant women, both Indigenous and non-Indigenous. 


\section{INTRODUCTION}

Rates of smoking in pregnancy have been declining in high-income countries, dropping from between $20-35 \%$ in 1980 , to $10-20 \%$ in $2000^{1}$. In Australia, $12 \%$ of all pregnant women in 2013 were smokers, but higher rates are reported for Indigenous Australian mothers $(47 \%)^{2}$.

There are several clinical guidelines to addressing smoking during pregnancy, e.g. the 5A's (Ask about tobacco use; Advise briefly to quit; Assess dependence and motivation to quit; Assist with support and medication; Arrange follow-up) $)^{3,4}$. A similar approach is the ABC (Ask; Brief advice; Cessation support ${ }^{5}$, and adapted for Indigenous Australian pregnant women, the ABCD includes an extra D component (Discuss psychosocial context of smoking $)^{6}$. A briefer approach is the AAR (Ask, Advise, Refer) ${ }^{7,8}$.

International Studies have shown that health professionals perform the Ask and Advise components fairly routinely but seldom the other components ${ }^{9-23}$. Up to a third of clinicians report delivering all of the $5 \mathrm{~A}^{\prime} \mathrm{s}^{9,10,16}$. Few studies included both General Practitioners (GPs) and Obstetricians ${ }^{16,19,24,25}$ : with either no difference in the provision of smoking cessation care (SCC) between the two physician groups ${ }^{16,19}$, or findings suggesting that GPs perform better $^{24,25}$.

Clinicians report facing multiple barriers to providing SCC to pregnant women, including: lack of time and administrative support; lack of knowledge and training; low confidence in personal skills; and a perception that smoking cessation interventions are not effective ${ }^{9,26}$. There is no current data on the level of smoking cessation care delivered to pregnant women by GPs or Obstetrician's in Australia.

This study aimed to examine: 1) Self-reported provision of SCC to pregnant women by GPs and Obstetricians in Australia; 2) Barriers and enablers to SCC and 3) Associations between physician group (GP/Obstetrician), knowledge, attitudes and the performance of SCC.

We hypothesise that Australian GPs and Obstetricians surveyed are lacking in their SCC provision to pregnant women who smoke; and that Australian GPs will perform better compared to Obstetricians.

\section{METHODS}

Design: A national cross-sectional survey. Two sampling methods were used: 1) A paper survey sent as an insert in the Royal Australian and New Zealand Collage of Obstetricians and Gynaecologists (RANZCOG) magazine (5571 Obstetricians and GPs with obstetric 
training); 2) An online survey emailed to a random sample of 500 members of the Royal Australian Collage of General Practitioners National Faculty of Aboriginal and Torres Strait Islander Health (RACGP NFATSIH) (with a special interest in Indigenous health).

The study was approved by the University of Newcastle Human Research Ethics Committee (18/03/2015: H-2015-0067).

Survey instrument: included professional and demographic characteristics, self-reported provision of SCC; and self-assessment of barriers and enablers (see on-line Supplementary File).

Self-reported Provision of SCC: was measured using 5-point Likert scales (Never (0\%); Occasional (1-25\%); Sometimes (26-50\%); Often (51-75\%); Always (76-100\%)) on the various components included in the 5A's, ABCD and AAR. Performing all the 5A's, ABCD, or AAR 'often \& always' was categorised as 'Yes' if the participant answered 'often' or 'always' to all relevant components. Other components of SCC such as prescription of NRT and involvement of family members were measured with the same 5-point Likert Scale. Barriers and enablers to SCC: were measured using the Theoretical Domains Framework (TDF). This is a validated and integrative theoretical framework that covers a range of domains relevant to professional practices and behaviour change ${ }^{27}$. Six domains using a total of 9 statements were measured on a 5-point Likert Scale (strongly disagree to strongly agree) including: 'Beliefs about Capabilities' (Confidence in counselling and in prescribing NRT), 'Optimism', 'Beliefs about Consequences' (benefit relationship), Goals/Plans' (high priority), 'Environmental Context and Resources' (sufficient time, resources, and workplace routine), 'Emotions' (comfortable raising the issue). The Knowledge domain was measured with one question ("Have you read any of the following guidelines? with 5 named), and was recategorised as 'reading any guideline' Yes/No.

Analysis: was performed with SPSS v24. We performed a descriptive analysis using counts and percentages for categorical measures. Univariate analysis was performed using Pearson's Chi-square test for categorical measures (with post-hoc comparisons using Bonferroni correction).

Dimension reduction for TDF statements was achieved with factor analysis, using Maximum likelihood method with Promax rotation. Factor means were then computed using included statements.

Logistic regression was performed separately for performing all the 5A's 'often \& always', and performing the AAR 'often \& always'. We included clinically relevant variables - 
physician group; medical practice remoteness; reading any guideline; and TDF factors after reduction. Complete case analysis was performed.

\section{RESULTS}

Sample characteristics: A total of 378 clinicians completed the survey (42 NFATSIH GPs, 157 RANZCOG GPs and 178 RANZCOG Obstetricians; response rate 6.2\%). Participants came from all Australian states and territories. Sixty two percent $(n=235)$ were female, $83 \%$ $(n=313)$ never smoked, and 1.9\% $(n=7)$ were current smokers. Fifty five percent $(n=210)$ had over 20 years of experience. Few $(5.4 \%, n=20)$ worked in remote $\operatorname{areas}^{28}, 63 \%(n=234)$ in urban settings, and 31.5\% $(\mathrm{n}=117)$ in regional. Only $7.8 \%(\mathrm{n}=29)$ catered for a population that was over $30 \%$ Indigenous, more from the NFATIH GPs $(28.9 \%, \mathrm{n}=11)$, than from RANZCOG GPs $(9.6 \%, n=15 ; \mathrm{p}=0.006)$, or Obstetricians $(1.7 \%, \mathrm{n}=3 ; \mathrm{p}<0.001)$.

Self-reported Provision of SCC: Over 75\% reported 'always' performing the Ask and Advise components, and less than a third (33\%) 'always' performing the rest of the components (Table 1). Less NFATSIH GPs reported 'always' referring their patients $(7.1 \%$, $\mathrm{n}=2)$ compared to RANZCOG GPs $(21.1 \%, \mathrm{n}=32 ; \mathrm{p}=0.114)$; and Obstetricians $(34.7 \%, \mathrm{n}=61$; $\mathrm{p}=0.003)$. Performing all the 5A's, ABCD, and AAR 'always' was stated by $1.6 \%(\mathrm{n}=6), 1.4 \%$ $(\mathrm{n}=5)$, and $20.2 \%(\mathrm{n}=76)$, respectively.

Performing all the 5A's 'often and always' was stated by $19.6 \%(n=74) ; 15.6 \%(n=59)$ for the ABCD; and 49.2\% $(n=186)$ for the AAR.

Barriers and enablers to SCC: Almost all clinicians (98\%) reported that addressing smoking during pregnancy is a high priority, and that they feel comfortable raising the issue with a pregnant woman (95\%). TDF statements receiving the lowest agreement (agree \& strongly agree) were having sufficient time (41\%), sufficient resources (47.5\%) and optimism of intervention effectiveness (35\%). Dimension reduction revealed two factors: 1) 'Internal influences' including confidence in counselling, confidence in prescribing NRT, optimism, sufficient time and resources; 2) 'External influences' including high priority, benefit relationship, workplace routine, and comfortable raising the issue.

Associations between knowledge and attitudes and performance of SCC: Table 2 details the crude and adjusted Odds Ratio (OR) for performing all the 5A's 'often \& always' and performing the AAR 'often \& always'. Compared to NFASTIH GPs, being an Obstetrician was associated with lower performance of all the 5A's (Adjusted OR 0.2 (95\% CI 0.08, 0.5), 
p<0.001), but with a higher performance of AAR (Adjusted OR 39.43 (95\% CI 8.6, 178.9), $\mathrm{p}<0.001)$. No difference was found between the performance of the RANZCOG GPs and Obstetricians. 'Internal influences' were associated with a higher performance of all the 5A's (Adjusted OR 2.69 (95\% CI 1.5, 4.8), p<0.001), whereas ‘External influences' were associated with a higher performance of AAR (Adjusted OR 1.7 (95\% CI 1, 2.8), p=0.035).

\section{DISCUSSION}

In this sample of GPs and Obstetricians in Australia, performance of SCC in pregnancy, aside from the Ask and Advise components, is low and variable, ranging from 4-33\%. Internal influences (including high confidence in counselling and prescribing NRT, higher optimism, sufficient time and resources) were associated with a higher performance of all the 5A's, while External influences (high priority, workplace routine, benefit to relationship, and comfortable raising the issue) were associated with a higher performance of the AAR. Physician group was also associated with performance, with Obstetricians performing the AAR better, and the 5A's less well, compared to NFATSIH GPs.

These findings are consistent with similar studies from other countries, with health providers providing Ask and Advise components more than with the other components of $\mathrm{SCC}^{9-23}$. The barriers reported in this study are very similar to those cited in a non-systematic review ${ }^{9}$ : lack of time; low confidence in personal skills; and a perception that smoking cessation interventions are not effective ${ }^{9,26}$. Other studies have examined the associations of different barriers to the provision of the 5A's, showing that specific barriers such as lack of resources ${ }^{16}$, or perceived impact of counselling ${ }^{29}$, affect the overall performance of the $5 \mathrm{~A}$ 's. To the best of our knowledge, our research is the first to suggest which barriers influence the different approaches to SCC in pregnancy, such as the 5A's versus the AAR.

Performing all the required 5A's was done by less than $20 \%$ of participants and was associated with barriers that are internal such as low confidence and low optimism. These need to be addressed by specific behaviour change interventions at the physician level including more precise training, and providing adequate resources. Performance of the shorter, more practical, AAR was higher, with almost 50\% performing this at least 'often'. This may suggest that the AAR approach could be easier to implement. External influences such as workplace routine and placing this topic as a high priority could be addressed through systematic interventions at the service level. Although perceived lack of time was grouped 
through the dimension reduction with the internal influences, this factor might be better addressed on a more systematic level, through adequate referral pathways.

The findings that NFASTIH GPs are performing the 5As better than Obstetricians or other GPs might reflect the importance of this topic in the population they treat. However, the low referral rates reported by this physician group require special attention. A Quitline is provided in Australia, with Aboriginal counsellors available. Currently there is no data on Indigenous pregnant women's views or utilization of this method. This is an area for further research.

Implication for policy and practice: Improving provision of the 5A's approach should focus on better training for GPs and Obstetricians, designed to improve confidence and optimism. Although the highest performance level was demonstrated by NFATSIH GPs, these levels are still low. The feasibility of training clinicians in the ABCD approach needs to be explored with those working with Indigenous pregnant mothers.

Improving the provision of the AAR approach might be easier to implement in view of the higher overall performance of this approach. It should be a priority to ensure easy, effective and acceptable referral mechanisms are in place. More research is needed specifically on the acceptability of the Quitline for pregnant women, both Indigenous and non-Indigenous. More explicit strategies could be put in place to ensure physicians refer women, and that the women are supported to use it. There may be a need to explore other referral options that are more intensive and individually tailored, such as to specialist cessation clinics. Studies have suggested that a more holistic approach that addresses the multiple stressors and challenges to quitting is needed, framing this more as a social matter that needs to be addressed in community settings, rather than just in the health sector ${ }^{6,30,31}$. This might be even more important in the Indigenous population, where medical services are often supplied through Aboriginal Community Controlled Health Services.

Limitations and Strengths: A limitation of this work is the low response rate, indicating this sample may not be generalizable to all Australian GPs and Obstetricians. In spite of this, these findings are consistent with other surveys globally ${ }^{9-23}$, supporting the cautious assumption that this is a true or over-estimation of actual practices. The low response rate needs to be kept in mind when interpreting these findings, and these results need to be confirmed by a larger more representative sample. Another limitation is the lack of data regarding previous training. This needs to be addressed in further research. One strength of 
this study was that it was a national survey, covering all states, and different settings. Another strength is that we included a subsample of GPs that are involved in Indigenous Health. This was justified as Australian Indigenous women have the highest rates of smoking during pregnancy $^{2}$.

Conclusions: In summary, performance in 'Assess', Assist' and 'Follow-up' aspects of SCC is low. Training GPs and Obstetricians should focus on improving internal influences such as confidence and optimism. Interventions on the service level may lead to higher rates of referral, and improve the implementation of the AAR approach. Further research is needed in this area, specifically in the Indigenous population.

Acknowledgments: We would like to acknowledge Prof Yvonne Cadet James and Dr Marilyn Clarke for their input in the early stages of designing this study; and Ms Harshani Jayasinghe for assisting with the early versions of the survey. 
Table 1: Self-Reported Provision of Smoking Cessation Care, $\mathrm{n}(\%)$

\begin{tabular}{|c|c|c|c|c|c|}
\hline $\begin{array}{l}\text { Total sample ( } n=378) \\
\text { (missing } n, \%)\end{array}$ & $\begin{array}{l}\text { Always } \\
\text { (76-100\% } \\
\text { of the time) }\end{array}$ & $\begin{array}{l}\text { Often } \\
\text { (51-75\%) }\end{array}$ & $\begin{array}{l}\text { Sometimes } \\
(26-50 \%)\end{array}$ & $\begin{array}{l}\text { Occasional } \\
(1-25 \%)\end{array}$ & $\begin{array}{l}\text { Never } \\
(0 \%)\end{array}$ \\
\hline $\begin{array}{l}\text { Ask about smoking } \\
\text { status (missing } n=3 \text {, } \\
0.8 \% \text { ) }\end{array}$ & $290(77.3 \%)$ & 67 (17.9\%) & $14(3.7 \%)$ & $2(0.5 \%)$ & $2(0.5 \%)$ \\
\hline $\begin{array}{l}\text { Give brief advise to quit } \\
\text { if smoking (missing } n=8 \text {, } \\
2.1 \% \text { ) }\end{array}$ & 276 (74.6\%) & $73(19.7 \%)$ & $13(3.5 \%)$ & 4 (1.1\%) & 4 (1.1\%) \\
\hline $\begin{array}{l}\text { Assess nicotine } \\
\text { dependence (missing } \\
n=6,1.6 \%)\end{array}$ & $90(24.2 \%)$ & 89 (23.9\%) & 66 (17.7\%) & 47 (12.6\%) & 80 (21.5\%) \\
\hline $\begin{array}{l}\text { Provide Cessation } \\
\text { support to smokers } \\
\text { (Assist) (missing } n=6, \\
1.6 \%)\end{array}$ & 125 (33.6\%) & $112(30.1 \%)$ & $58(15.6 \%)$ & 43 (11.6\%) & 34 (90.1\%) \\
\hline $\begin{array}{l}\text { Follow-up within } 2 \\
\text { weeks (Arrange) } \\
\text { (missing } n=5,1.3 \% \text { ) }\end{array}$ & $26(7 \%)$ & 63 (16.9\%) & 104 (27.9\%) & $88(23.6 \%)$ & $92(24.7 \%)$ \\
\hline $\begin{array}{l}\text { Prescribe/recommend } \\
\text { NRT to assist quitting } \\
\text { (missing } n=7,1.9 \% \text { ) }\end{array}$ & 41 (11.1\%) & $76(20.5 \%)$ & $89(24 \%)$ & 72 (19.4\%) & 93 (25.1\%) \\
\hline $\begin{array}{l}\text { Discuss their } \\
\text { psychosocial context of } \\
\text { smoking (missing } n=6 \text {, } \\
1.6 \% \text { ) }\end{array}$ & $82(22 \%)$ & $106(28.5 \%)$ & 69 (18.5\%) & 57 (15.3\%) & 58 (15.6\%) \\
\hline $\begin{array}{l}\text { Referral to } \\
\text { Quitline/specialist } \\
\text { service (missing n=21, } \\
5.6 \% \text { ) }\end{array}$ & 95 (26.6\%) & $99(27.7 \%)$ & $57(16 \%)$ & 47 (13.2\%) & 59 (16.5\%) \\
\hline $\begin{array}{l}\text { Involving family } \\
\text { members in } \\
\text { counselling/tobacco } \\
\text { management (missing } \\
n=6,1.6 \% \text { ) }\end{array}$ & $15(4 \%)$ & $57(15.3 \%)$ & 87 (23.4\%) & $143(38.4 \%)$ & 70 (18.8\%) \\
\hline
\end{tabular}


Table 2: Crude and Adjusted Odds Ratio (OR) for performing all the 5A's and the AAR 'often \& always'

\begin{tabular}{|c|c|c|c|c|c|c|c|c|c|c|}
\hline \multirow[b]{3}{*}{ Variable } & \multicolumn{5}{|c|}{ Preforming all the 5 As often or always $(n=340)$} & \multicolumn{5}{|c|}{ Performing all the AAR often or always $(n=346)$} \\
\hline & \multirow{2}{*}{$\begin{array}{c}\text { Performing } \\
\text { all the } 5 A s \\
\text { often or } \\
\text { always } \\
n(\%)\end{array}$} & \multicolumn{2}{|c|}{ Crude } & \multicolumn{2}{|c|}{ Adjusted } & \multirow{2}{*}{$\begin{array}{c}\text { Performing } \\
\text { all the ARR } \\
\text { often or } \\
\text { always } \\
\mathrm{n}(\%)\end{array}$} & \multicolumn{2}{|c|}{ Crude } & \multicolumn{2}{|c|}{ Adjusted } \\
\hline & & $\begin{array}{l}\text { Odds Ratio } \\
\text { (95\%) }\end{array}$ & $\begin{array}{c}\text { P- } \\
\text { value }\end{array}$ & $\begin{array}{c}\text { Odds Ratio } \\
\text { (95\%) }\end{array}$ & $\begin{array}{c}\text { P- } \\
\text { value }\end{array}$ & & $\begin{array}{c}\text { Odds Ratio } \\
(95 \%)\end{array}$ & $\begin{array}{c}\text { P- } \\
\text { value }\end{array}$ & $\begin{array}{c}\text { Odds Ratio } \\
(95 \%)\end{array}$ & $\begin{array}{c}\text { P- } \\
\text { value }\end{array}$ \\
\hline Physician Group & & & $<0.001$ & & $<0.001$ & & & $<0.001$ & & $<0.001$ \\
\hline RANZCOG OBS & $23(13.4 \%)$ & Ref. & & Ref. & & $101(57 \%)$ & Ref. & & Ref. & \\
\hline RANZCOG GPS & $30(19.5 \%)$ & $\begin{array}{c}1.567 \\
(0.86,2.83)\end{array}$ & 0.138 & $\begin{array}{c}0.973 \\
(0.18,1.96)\end{array}$ & 0.938 & $82(52.2 \%)$ & $\begin{array}{c}0.823 \\
(0.53,1.26)\end{array}$ & 0.376 & $\begin{array}{c}0.635 \\
(0.37,1.08)\end{array}$ & 0.097 \\
\hline NFATSIH GPS & $20(50 \%)$ & $\begin{array}{c}6.478 \\
(3.03,13.8)\end{array}$ & $<0.001$ & $\begin{array}{c}4.79 \\
(1.95,11.74)\end{array}$ & 0.001 & $2(4.8 \%)$ & $\begin{array}{c}0.038 \\
(0.009,0.1)\end{array}$ & $<0.001$ & $\begin{array}{c}0.025 \\
(0.006,0.1)\end{array}$ & $<0.001$ \\
\hline $\begin{array}{l}\text { Medical Practice } \\
\text { Remoteness }\end{array}$ & & & 0.074 & & 0.297 & & & 0.019 & & 0.233 \\
\hline Urban & $40(17.8 \%)$ & Ref. & & Ref. & & $126(54 \%)$ & Ref. & & Ref. & \\
\hline Regional & $31(27 \%)$ & $\begin{array}{c}1.7 \\
(0.99,2.91) \\
\end{array}$ & 0.05 & $\begin{array}{c}1.12 \\
(0.59,2.12) \\
\end{array}$ & 0.732 & $51(43.6 \%)$ & $\begin{array}{c}0.65 \\
(0.42,1.0) \\
\end{array}$ & 0.065 & $\begin{array}{c}0.80 \\
(0.47,1.37) \\
\end{array}$ & 0.422 \\
\hline Remote & $2(10 \%)$ & $\begin{array}{c}0.51 \\
(0.11,2.3) \\
\end{array}$ & 0.384 & $\begin{array}{c}0.27 \\
(0.04,1.6) \\
\end{array}$ & 0.152 & $5(25 \%)$ & $\begin{array}{c}0.28 \\
(0.1,0.8) \\
\end{array}$ & 0.018 & $\begin{array}{c}0.381 \\
(0.11,1.21) \\
\end{array}$ & 0.104 \\
\hline \multicolumn{11}{|c|}{ Reading any guideline } \\
\hline No & $20(12.8 \%)$ & Ref. & & Ref. & & 65 (40.1\%) & Ref. & & Ref. & \\
\hline Yes & $54(25.6 \%)$ & $\begin{array}{c}2.33 \\
(1.33,4.1) \\
\end{array}$ & 0.003 & $\begin{array}{c}2.09 \\
(1.08,4.04)\end{array}$ & 0.027 & $121(56 \%)$ & $\begin{array}{c}1.92 \\
(1.27,2.9) \\
\end{array}$ & 0.002 & $\begin{array}{c}2.73 \\
(1.67,4.45) \\
\end{array}$ & $<0.001$ \\
\hline Internal barriers* & $\begin{array}{c}\text { Mean(SD) } \\
\text { Yes 3.7(0.6) } \\
\text { No 3.3(0.6) }\end{array}$ & $\begin{array}{c}3.47 \\
(2.16,5.57)\end{array}$ & $<0.001$ & $\begin{array}{c}2.69 \\
(1.52,4.78)\end{array}$ & 0.001 & $\begin{array}{c}\text { Mean(SD) } \\
\text { Yes 3.4(0.6) } \\
\text { No 3.3(0.7) }\end{array}$ & $\begin{array}{c}1.18 \\
(0.86,1.62)\end{array}$ & 0.296 & $\begin{array}{c}1.17 \\
(0.76,1.81)\end{array}$ & 0.465 \\
\hline External barriers\$ & $\begin{array}{c}\text { Mean(SD) } \\
\text { Yes 4.5(0.4) } \\
\text { No 4.2(0.5) }\end{array}$ & $\begin{array}{c}3.275 \\
(1.81,5.91)\end{array}$ & $<0.001$ & $\begin{array}{c}1.989 \\
(0.97,4.06)\end{array}$ & 0.059 & $\begin{array}{c}\text { Mean(SD) } \\
\text { Yes 4.3(0.5) } \\
\text { No 4.2(0.6) }\end{array}$ & $\begin{array}{c}1.57 \\
(1.05,2.33)\end{array}$ & 0.027 & $\begin{array}{c}1.71 \\
(1.03,2.8)\end{array}$ & 0.035 \\
\hline
\end{tabular}

${ }_{*}^{*}$ Internal barriers includes confidence in counselling, confidence in prescribing NRT, optimism in intervention effectiveness, sufficient time and resources

\$External barriers includes high priority, benefit relationship, workplace routine, comfortable raising the issue 


\section{DECLARATION OF INTERESTS}

Dr Bar Zeev has received fees for lectures in the past (years 2012-2015) from Novartis NCH (distributes NRT in Israel). She has not received any fees from pharmaceutical companies in Australia.

No other co-authors have conflicts of interest.

\section{FUNDING}

This work has been funded by RACGP Chris Silagy Scholarship (Gould) and an NHMRC Early Career Fellowship (Gould), and Hunter Cancer Research Alliance PhD scholarship (Bar Zeev). BB is supported by a NHMRC Career Development Fellowship and the University of Newcastle, Faculty of Health and Medicine, Gladys M Brawn Career Development Fellowship. 


\section{REFERENCES:}

1. Coleman T, Chamberlain C, Davey MA, Cooper SE, Leonardi-Bee J. Pharmacological interventions for promoting smoking cessation during pregnancy. Cochrane Database Syst Rev. 2015;12:CD010078.

2. AlHW 2015. Australia's mothers and babies 2013-in brief. Canberra: AlHW.2015.

3. The Agency for Health Care Policy and Research Smoking Cessation Clinical Practice Guideline. Jama. 1996;275(16):1270-1280.

4. Fiore MC (Chair GP. Treating tobacco use and dependence: 2008 update. In: Services. USDoHaH, Service PH, eds2008.

5. McRobbie $\mathrm{H}$, Bullen $\mathrm{C}$, Glover M, et al. New Zealand smoking cessation guidelines. The New Zealand medical journal. 2008;121(1276):57-70.

6. Gould GS, Bittoun R, MJ. C. A Pragmatic Guide for Smoking Cessation Counselling and the Initiation of Nicotine Replacement Therapy for Pregnant Aboriginal and Torres Strait Islander Smokers Journal of Smoking Cessation. 2015;10:96-105.

7. Vidrine J, Shete $\mathrm{S}, \mathrm{Cao} \mathrm{Y}$, et al. Ask-advise-connect: A new approach to smoking treatment delivery in health care settings. JAMA Intern Med. 2013;173(6):458-464.

8. Crane R. The most addictive drug, the most deadly substance: smoking cessation tactics for the busy clinician. Primary care. 2007;34(1):117-135.

9. Okoli CT, Greaves L, Bottorff JL, Marcellus LM. Health care providers' engagement in smoking cessation with pregnant smokers. J Obstet Gynecol Neonatal Nurs. 2010;39(1):64-77.

10. Chang JC, Alexander SC, Holland CL, et al. Smoking is bad for babies: obstetric care providers' use of best practice smoking cessation counseling techniques. Am J Health Promot. 2013;27(3):170-176.

11. Price JH, Jordan TR, Dake JA. Obstetricians and gynecologists' perceptions and use of nicotine replacement therapy. J Community Health. 2006;31(3):160-175.

12. Glover M, Paynter J, Bullen C, Kristensen K. Supporting pregnant women to quit smoking: postal survey of New Zealand general practitioners and midwives' smoking cessation knowledge and practices. N Z Med J. 2008;121(1270):53-65.

13. Cooke M, Mattick RP, Campbell E. The influence of individual and organizational factors on the reported smoking intervention practices of staff in 20 antenatal clinics. Drug Alcohol Rev. 1998;17(2):175-185.

14. Condliffe L, McEwen A, West R. The attitude of maternity staff to, and smoking cessation interventions with, childbearing women in London. Midwifery. 2005;21(3):233-240.

15. Grimley DM, Bellis JM, Raczynski JM, Henning K. Smoking cessation counseling practices: a survey of Alabama obstetrician-gynecologists. South Med J. 2001;94(3):297-303.

16. Hartmann KE, Wechter ME, Payne P, Salisbury K, Jackson RD, Melvin CL. Best practice smoking cessation intervention and resource needs of prenatal care providers. Obstet Gynecol. 2007;110(4):765-770.

17. Hickner J, Cousineau A, Messimer S. Smoking cessation during pregnancy: strategies used by Michigan family physicians. J Am Board Fam Pract. 1990;3(1):39-42.

18. Jordan TR, Dake JR, Price JH. Best practices for smoking cessation in pregnancy: do obstetrician/gynecologists use them in practice? J Womens Health (Larchmt). 2006;15(4):400-441.

19. Moran S, Thorndike AN, Armstrong K, Rigotti NA. Physicians' missed opportunities to address tobacco use during prenatal care. Nicotine Tob Res. 2003;5(3):363-368.

20. Mullen PD, Pollak KI, Titus JP, Sockrider MM, Moy JG. Prenatal smoking cessation counseling by Texas obstetricians. Birth. 1998;25(1):25-31. 
21. Price JH, Jordan TR, Dake JA. Perceptions and use of smoking cessation in nurse-midwives' practice. J Midwifery Womens Health. 2006;51(3):208-215.

22. Coleman-Cowger VH, Anderson BL, Mahoney J, Schulkin J. Smoking cessation during pregnancy and postpartum: practice patterns among obstetrician-gynecologists. J Addict Med. 2014;8(1):14-24.

23. De Wilde K, Tency I, Steckel S, Temmerman M, Boudrez H, Maes L. Which role do midwives and gynecologists have in smoking cessation in pregnant women? - A study in Flanders, Belgium. Sex Reprod Healthc. 2015;6(2):66-73.

24. Helwig AL, Swain GR, Gottlieb M. Smoking cessation intervention: the practices of maternity care providers. J Am Board Fam Pract. 1998;11(5):336-340.

25. Clasper $P$, White $M$. Smoking cessation interventions in pregnancy: practice and views of midwives, GPs and obstetricians. Health Education Journal. 1995;54(2):150-162.

26. Baxter S, Everson-Hock E, Messina J, Guillaume L, Burrows J, Goyder E. Factors relating to the uptake of interventions for smoking cessation among pregnant women: a systematic review and qualitative synthesis. Nicotine \& Tobacco Research. 2010;12(7):685-694.

27. Cane J, O'Connor D, Michie S. Validation of the theoretical domains framework for use in behaviour change and implementation research. Implement Sci. 2012;7:37.

28. Health AGDo. Australian Standard Geographical Classification - Remoteness Areas (ASGC-RA 2006) 2006; http://www.doctorconnect.gov.au/internet/otd/publishing.nsf/content/raintro.

29. Mullen PD, Pollak KI, Titus JP, Sockrider MM, May JG. Prenatal smoking cessation counselling by Texas obstetricians. Birth: Issues in Perinatal Care. 1998;25(1):25-31.

30. Boucher J, Konkle A. Understanding Inequalities of Maternal Smoking-Bridging the Gap with Adapted Intervention Strategies. International Journal of Environmental Research and Public Health. 2016;13(3):282.

31. Flemming K, Graham H, McCaughan D, Angus K, Sinclair L, Bauld L. Health professionals' perceptions of the barriers and facilitators to providing smoking cessation advice to women in pregnancy and during the post-partum period: a systematic review of qualitative research. BMC Public Health. 2016;16(1):290. 